DOI: https://doi.org/10.32689/2618-0065-2020-2(4)-63-72

Василенко Надія Володимирівна, доктор пед.наук, професор, Заслужений вчитель України, зав. кафедри управління та адміністрування Комунальний вищий навчальний заклад «Вінницька академія неперервної освіти», 21100 м. Вінниця, вул. Грушевська , 13, тел. (0432)-55-65-68, mail:nadezhdavasilenko2016@gmail.com, https// orcid/0000-0002-1087-459.

\title{
АЛГОРИТМІЧНА КОМПЕТЕНТНОСТІ ФАХІВЦЯ З ПУБЛІЧНОГО УПРАВЛІННЯ: АЛГОРИТМІЧНІ ЗНАННЯ, АЛГОРИТМІЧНЕ МИСЛЕННЯ, АЛГОРИТМІЧНА КУЛЬТУРА
}

Анотація. У статті здійснено аналіз підходів до реформування засад публічного управління інформаційно - комунікаційними засобами шляхом алгоритмізації послідовних управлінських дій фахівця. Трансформація розкривається доцільністю формування алгоритмічної компетентності фахівців 3 публічного управління через набуття алгоритмічних компетенцій зі складання алгоритмів, алгоритмічного мислення їх виконання та використанням алгоритмічної культури щодо алгоритмічних приписів під час прийняття управлінських рішень.

Аналітичний огляд нормативної бази та сучасних підходів щодо послідовності дій фахівця з публічного управління за допомогою алгоритмів дає змогу визначить необхідність та доцільність розробки відповідної технології, що має стати зручним інструментом аналізу, вироблення ефективних управлінських рішень щодо їх розв'язання, яки нададуть можливість коригувати управлінські дії сучасного керівника. Окреслено законодавчі ініціативи та концепції, які визначають основний напрям держави щодо електронного врядування, організації електронного документообігу та Інтернет - взаємодії фахівців 3 публічного управління з громадськістю. Окремо визначені поняття «алгоритму», алгоритмічні компетенції, алгоритмічне мислення, алгоритмічна культура, компетентність, алгоритмічна компетентність.

На основі проведеного дослідження встановлено, що алгоритмічна компетентність фахівців, як складової інформаційно-цифрової компетентності висвітлює зв'язок між поняттями «алгоритмічні компетенції », «алгоритмічне мислення», «алгоритмічна культура», які забезпечують прийняття результату управлінських рішень . Розкрито взаємозв'язок між складанням алгоритмічних приписів в управлінні та складанням блок-схем у програмуванні. Показано доцільність використання такого зв'язку при прийнятті управлінського рішення фахівців з публічного управління з метою попередження їх помилок. 
Ключові слова: алгоритм, алгоритмічні компетенції, алгоритмічне мислення, алгоритмічна культура, алгоритмічна компетентність, інформаційноцифрова компетентність, компетентність, публічне управління, управлінські дії, управлінське рішення, попередження помилок.

Vasylenko Nadiya Volodymyrivna, doktor ped.nauk, profesor, Zasluzhenyy vchytel' Ukrayiny, zav. kafedry upravlinnya ta administruvannya Komunal'nyy vyshchyy navchal'nyy zaklad «Vinnyts'ka akademiya neperervnoyi osvity», 21100 Vinnytsya, st. Hrushevs'ka, 13, tel.(0432)-55-65-68, e-mail:nadezhdavasilenko2016@gmail.com, https// orcid /0000-0002-1087-459.

\section{ALGORITHMIC COMPETENCIES OF THE PUBLIC ADMINISTRATION SPECIALIST: ALGORITHMIC KNOWLEDGE, ALGORITHMIC THINKING, ALGORITHMIC CULTURE}

Abstract. The article analyzes the approaches to reforming the principles of the public administration of information and communication means by algorithmic sequencing of the administrative actions of a specialist. The transformation is revealed by the expediency of forming the algorithmic competence of the public administration specialists through the acquisition of algorithmic competencies for compiling algorithms, algorithmic thinking of their execution and the use of algorithmic culture for algorithmic prescriptions in making administrative decisions.

The analytical review of the regulatory framework and modern approaches to the sequence of actions of a specialist in the public administration using algorithms makes it possible to determine the need and expediency of developing appropriate technology, which should be a convenient tool for analysis, to develop effective administration decisions for their solution, which will allow to correct the administration actions of a modern leader. The legislative initiatives and concepts defining the main direction of the state regarding e-government, organization of electronic document circulation and Internet - interaction of the specialists in the public administration with the public are outlined. Separately are defined the concepts of “algorithm”, algorithmic competencies, algorithmic thinking, algorithmic culture, competence, algorithmic competence.

On the basis of the conducted research it is established that the algorithmic competence of specialists, as a component of information and digital competence, illuminates the connection between the concepts of "algorithmic competences", "algorithmic thinking”, "algorithmic culture”, which ensure the adoption of administration decisions. The relationship between the compilation of algorithmic control instructions and the compilation of flowcharts in programming is disclosed. The expediency of using such communication in the decision-making of the public administration specialists is shown to prevent their mistakes.

Keywords: algorithm, algorithmic competences, algorithmic thinking, algorithmic culture, algorithmic competence, information-digital competence, competence, public administration, administration actions, administration decision, mistake prevention. 
Постановка проблеми. Цифрові та мережеві технології постійно трансформуються, зокрема і в публічної сфері. Досвід управлінської діяльності показав, що багато хто вважає, особливо молодь, що інформатика потрібна тільки для того, щоб навчитися працювати на комп’ютерах, але це не так. Більшість осіб не усвідомлює, що кожна людина щодня зустрічається з безліччю задач від найпростіших і добре відомих до дуже складних. Для багатьох задач існують визначені правила (інструкції, команди), що пояснюють виконавцю, як розв’язувати дану проблему.

Практика засвідчила, що ці правила фахівець вивчав ще в школі та має можливості заздалегідь створити алгоритми самостійно в процесі розв'язування різних задачі. Чим точніше з часом будуть описано правила, тим швидше фахівець опанує ними і буде ефективніше їх застосовувати. У нашому житті ми постійно складаємо опис деякої послідовності дій, особливо це стосується сучасних керівників, для досягнення бажаного результату. Тому поняття алгоритму не $\epsilon$ для нас чимось новим і незвичайним. Але $є$ галузі, зокрема і галузь публічне управління та адміністрування, в яких поняття, властивості, складання та виконання алгоритмів використовуються неефективно.

Фахівець 3 публічного управління має використовувати сотні різних алгоритмів, деякі з них - алгоритми виконання управлінських дій, розв’язування ситуативних задач $з$ публічного управління тощо.

Аналіз останніх досліджень і публікацій. Вивчення поняття алгоритму починаеться в школьному курсі інформатики, яке вважается $є$ фундаментальним, тобто таким, котре не визначається через інші ще більш прості поняття [1].

Детальну характеристику навчального алгоритму дає Л. Фрідман. «Під навчальним алгоритмом ми будемо розуміти припис, користуючись яким будьякий фахівець, який має необхідні знання точно виконувати цей припис, правильно розв'яже будь-яку задачу такого виду» [1, с. 69; 2].

Ми з'ясували наукові джерела 3 проблематики дослідження 3 метою розкриття основного поняття «Алгоритм» та його значення у понятті розвитку алгоритмічної компетентності фахівця з публічного управління, а саме [3;4]:

- алгоритм - це формулювання правил тільки для виконання чотирьох арифметичних дій над багатоцифровими числами (визначили правила вибору алгоритмів) [4]. Та разом з тим, не кожна інструкиія або послідовність дій може називатися алгоритмом.

- алгоритм - це позначення послідовності дій, які приводять до розв'язання різних практичних, зокрема і управлінських, задач (визначили правила створення алгоритмів та їх виконавців) [4]. Будь-який виконавець (i комп'ютер зокрема) може виконувати тільки обмежений набір операчій.

- алгоритм це визначення зрозуміле і точне розпорядження виконавцю про виконання послідовності дій, спрямованих на досягнення зазначеної мети чи на вирішення поставленої задачі (визначили способи використання алгоритмів). $B$ цьому означенні використовується поняття “виконавець”. Що це означає? 
Під виконавцем алгоритму ми розуміємо будь-яку істоту (живу чи неживу), яка спроможна виконати алгоритм. Все залежить від того, якої мети ми намагаємося досягнути. Наприклад: риття ями (виконавці - людина або екскаватор), розв’язування математичної задачі (учень або комп’ютер), розв’язання управлінського рішення (більш керівник ніж комп’ютер ) [4].

- алгоритм це розкриття його ознаки та властивостей (визначили результат алгоритмів). Алгоритм має певні властивості, разом з тим, не кожна інструкція або послідовність дій може називатися алгоритмом. Вивчення наукових джерел надало можливість визначити основні ознаки алгоритму.

До них віднесено[4;5]:

1. Зрозумілість (тобто розуміти кожну з команд, що входять до алгоритму для досягнення поставленої мети).

2. Визначеність (однозначність, зрозумілий алгоритм все ж таки не повинен містити вказівки, зміст яких може сприйматися неоднозначно, що потрібно робити на наступному кроці).

3. Дискретність (алгоритм задає повну послідовність дій, які необхідно виконувати для розв’язання задачі.

4. Масовість (дуже важливо, щоб складений алгоритм забезпечував розв’язання не однієї окремої задачі, а міг виконувати розв’язання широкого класу задач даного типу).

5. Результативність ( взагалі кажучи, очевидно, що виконання будь-якого алгоритму повинне завершуватися одержанням кінцевих результатів). $\quad$ 6. Ефективність- (кожний крок алгоритму повинен бути виконаний точно за скінчений проміжок часу).

Дидактичні основи формування алгоритмічної компетентності фахівців визначили А.Н.Капіносов та В.В Корольський [6]. В організації превентивної діяльності алгоритмічні приписи $є$ одним із важливих засобів попередження помилок особистості. Ми тісно пов’язуємо між собою поняття «інформаційноцифрова компетентність», «алгоритмічна компетентність», «алгоритмічне мислення», «запобігання професійних помилкам» фахівців. В роботі [6] автори виділили рівні алгоритмічної компетентності, вважаючи, що на початковому, середньому та достатньому рівні, фахівці повинні вміти використовувати алгоритми, а на високому - їх складати .

Метою статті є дослідити розвиток алгоритмічної компетентності в рамках інформаційно-цифрової компетентності фахівців з публічного управління з метою попередження появи помилок при прийнятті управлінських рішень.

Виклад основного матеріалу. Аналіз основних ознак алгоритму надало можливість визначити основні ознаки властивостей алгоритму. Ми встановили, що для роботи багатьох програм необхідно задавати початкові значення: аргумент (передає значення для виконання алгоритму), результат (це величини, значення яких одержуються внаслідок виконання алгоритму), проміжні величини (це величини, які додатково вводяться в ході розробки алгоритму). 
Тепер залишається з'ясувати, яким чином можна подати алгоритм виконавцю. Існує кілька методів запису алгоритмів, вибір яких залежить від виконавця та того, хто його задає [4;5].

Першій спосіб - це словесний опис алгоритму. Другий спосіб - це подача алгоритму у вигляді таблиць, формул, схем, малюнків тощо. Третій спосіб - запис алгоритмів за допомогою блок-схеми. Цей метод був запропонований в інформатиці для наочності представлення алгоритму за допомогою набору спеціальних блоків. Четвертий спосіб - алгоритмічні мови (псевдокоди). Ці мови мають жорстко визначений синтаксис і вже максимально наближені до машинної мови (мови програмування). П'ятий спосіб максимально наближений до комп'ютера - це мови програмування. Справа в тому, що найчастіше в практиці виконавцем створеного людиною алгоритму являється машина і тому він повинен бути написаний мовою, зрозумілою для комп’ютера, тобто мовою програмування.

Розглянемо приклад розв'язання ситуативної задачі за допомогою алгоритму Евклиду [5], зміст якого в наступному:

1.Знайти найбільший спільний дільник двох натуральних чисел $\mathrm{m}$ i $\mathrm{n}$ (алгоритм Евкліда). Складемо алгоритм розв'язання цієї задачі, який базується на тій властивості, що якщо $\mathrm{m}>\mathrm{n}$, то найбільший спільний дільник чисел $\mathrm{m}, \mathrm{n}$ такий самий, як і чисел m-n, n.

Алгоритм (за Евклидом) буде таким:

1. Якщо числа рівні, то взяти будь-яке з них за відповідь, в іншому випадку продовжити виконання алгоритму;

2. Визначити більше із чисел;

3. Замінити більше число різницею більшого і меншого чисел;

4. Почати алгоритм спочатку.

За допомогою першого способу (словесний опис алгоритму) розв'язуємо розв’язуємо наступну задачу.

Для цього створюємо алгоритм:

1.Якщо є декілька варіантів розв'язання проблеми, то вибираємо оптимальні варіанти розв'язання управлінського завдання, на нашу думку,

2. Складаємо алгоритм (послідовність виконання управлінських дій)

3.Продовжуємо виконання алгоритмів.

4. Визначаємо найбільш ефективні управлінські дії.

5.Обгрунтовуємо та зазначаємо результат.

6. Якщо ні, то починаємо виконання алгоритму спочатку.

У дослідженні ми надаємо особливого значення складовим алгоритмічної компетентності фахівців з публічного управління: алгоритмічні компетенції

( формуванню умінь фахівця з публічного управління структурувати дані); алгоритмічне мислення (діяти за алгоритмом) та алгоритмічна культура

( якості складати і виконувати алгоритми ). 
Ми вважаємо, що алгоритмічні уміння є засобом попередження помилок фахівців, структурувати набір інструкцій, які описують порядок дій виконавця; щоб досягти якісного результату розв'язання задачі за скінченну кількість дій. Алгоритмічне мислення фахівця допомагає чітко побачити кроки, що ведуть до мети, замітити всі перешкоди і уміло їх обійти.

У науково-методичній літературі основою алгоритмічного мислення вважається здатність до конструювання алгоритмів. В.Копаєв визначає алгоритмічне мислення як «систему мисленнєвих способів дій, прийомів, методів і відповідних їм мисленнєвих стратегій, які спрямовані на розв’язування як теоретичних, так і практичних задач і результатом яких $є$ алгоритми як специфічні продукти людської діяльності»[5, с.1]. Формування алгоритмічного мислення тісно пов'язане з формуванням загального уміння розв'язувати задачі. Оскільки, щоб задати загальний спосіб розв'язування класу задач у вигляді алгоритму, потрібно спочатку знайти загальний спосіб, а потім дослідити можливість опису цього способу у вигляді конструктивних, однозначно зрозумілих послідовних кроків [6 ].

Основою алгоритмічної компетентності $є$ алгоритмічна культура. Більшість науковців поняття алгоритмічної культури трактують як комплекс особистісних якостей і певний рівень алгоритмічного мислення, які забезпечують [5;6]:

1) розуміння ролі алгоритмів у різних видах діяльності;

2) уміння діяти за заданим алгоритмом (у розгорнутій чи згорнутій формі);

3) уміння здійснювати вибір і застосовувати алгоритми у своїй діяльності;

4) уміння конструювати алгоритми;

5) уміння описувати спосіб розв’язувати задачі у вигляді алгоритмічного припису.

Алгоритмічна культура визначає особистісних якостей і певний рівень алгоритмічного мислення, які $\epsilon$ основою алгоритмічної компетентності особистості.

Проаналізуємо більш детальніше основні складові поняття алгоритмічної компетентності, яка $\epsilon$, як i інші складової професійної компетентності, але одиничними поняттями якої $€$ компетентність, як спроможність особистості сприймати індивідуальні та соціальні потреби і відповідати на них, кваліфіковано здійснювати діяльність у будь-якому напрямі, виконувати певні завдання або роботу. Поняття «компетентність», «формування компетентності» прийшли до нас із західного педагогічного словника й останніми роками $\epsilon$ предметом дослідження багатьох міжнародних організацій, які виробляють свої рекомендації щодо формування компетентності фахівців. Виявилось, що результати освіти не задовольняють вимоги суспільства, i насамперед роботодавців $[1 ; 5 ; 6]$.

Проведені дослідження виявили, що на сучасному ринку праці потрібні люди 3 іншим, набагато ширшим, аніж тільки пізнавальні, набором якостей i можливостей, які, по суті, і визначають компетентність людини до IКТ. ІКТ- 
компетентність включає в себе систему компетентностей, зокрема і алгоритмічну, за порядком виконання алгоритму послідовних алгоритмічних управлінських дій [3;6].

Це: технологічна компетентність (володіння сучасними засобами IКТ (пристроями і пакетами — «залізом» і «софтом») для розв’язування поточних задач у сьогоденному інформаційному суспільстві); дослідницька компетентність (передбачає володіння засобами ІКТ та методами застосувань i наукових досліджень у різних галузях знань); модельна компетентність (це володіння базовими поняттяи теоії моделей, поняттями комп'ютерного моделювання, усвідомлення комп'ютера як універсального засобу інформаційного моделювання); методологічна компетентність (це необмежені можливості і можливі обмеження застосування засобів IКТ для розв'язування соціально й індивідуально значимих задач сьогодні й у майбутньому) [4;6].

Дослідження встановили, що наведений вище перелік складових IKTкомпетентностей $є$ до певної міри зворотно рейтинговим (чим більший номер компетентності за наведеним списком, тим рейтинг вищий). Всі ці компетентності, на нашу думку, об'єднує алгоритмічна компетентність. Розглянемо детальніше саме сутності алгоритмічної компетентності.

Для компетентнісної освіти дуже важливим $є$ поняття набуття алгоритмічних компетенцій : це не засвоєння, не вивчення, не пізнання - це набуття. Компетентностей можна досягти тільки своєю особистою активною та продуктивною діяльністю (причому не тільки навчальною), особистою творчістю, особистим досвідом через пізнання соціального досвіду, його критичне осмислення, іншими словами, через своє неповторне особисте набуття. У понятті набуття знайшли своє відображення погляди сучасної педагогіки та психології, які визнають не на словах, а на практиці індивідуальну особистість кожного фахівця, неповторність індивідуального досвіду кожної особистості, які визнають продуктивною тільки освіту співробітництва, освіту, яка забезпечує індивідуальне творче бутя, зокрема і фахівця з публічного управління [6].

В організації превентивної діяльності алгоритмічні приписи $є$ одним із важливих засобів попередження помилок фахівців. Ми поділяємо погляди науковців, однак вважаємо за необхідне навчати фахівців складати та застосовувати алгоритми на всіх рівнях публічного управління, основої яких $є$ програмування. Саме у програмуванні - чітка послідовність дій (команд) спрямована на досягнення поставленої мети чи розв’язування різних типів управлінських завдань [2;3].

Аналіз наукової літератури показав, що у створенні комп’ютерних програм використовують три типи алгоритмів: лінійні алгоритми, алгоритми 3 розгалуженням, алгоритми 3 повторенням [6]. В основу створення фахових алгоритмів ми покладаємо володіння елементарними основами програмування. Але при цьому допускаємо, що можно використовувати як графічний (блок-схеми) так i словесні (алгоритмічні приписи) способи. Використовуючи відповідні знання за 
курс середньої школи (з інформатики та математики), фахівцю доцільно знати як основні команди програмування можна вдало використовувати у публічному управлінні. Так, прикладами використання лінійних команд є: находження та зведення подібних складових завдань, узагальнення їх, розв'язування завдання декалькоми варіантами, аналіз результату і побудова графіків при потребі та прийняття управлінського рішення [5;6].

Команда розгалуження використовується під час виділення додаткових завдань (перевірка умови), їх узагальнення (аналіз умови), та розв'язування (оцінка результату за умовою завдання), тобто в тих завданнях де обов'язково під час його виконання завдання необхідно перевірити певну умову. Команду повторення можна використати, наприклад, у наступному завданні:

«Проаналізувати надання адміністративних послуг в соціальної сфері області та скласти заходи щодо ії покращення. Командою повторення може бути знайти додаткові відомості (як варіант надання адміністративних послуг в розвитку освіти, медицини, культури за останні п’ять років)».

Як показує практика для вирішення управлінських завдань фахівцями потрібно іх ознайомити зі складанням елементарних программ в умовах добування бакалаврської та магістерської вищої освіти фахівців 3 публічного управління. Доцільно показати як виглядає блок-схема, показати як можна подавати процес розв’язування управлінських завдань у вигляді блок-схем. Як показує досвід, фахівцям з публічного управління подобається алгоритмічні приписи подавати у вигляді блок-схем і навпаки.

Важливе значення при навчанні студентів, зокрема і спеціальності 281 Публічне управління та адміністрування, навчити створювати самостійно власний опорний конспект, в якому має бути зазначено мову блок-схем як найбільшу наочну із всіх «людських» мов, що використовуються для запису алгоритмів. Розробити, описати різні процеси та внести їх до конспекту. Зрозуміти, що цією мовою можна описати різні, фізичні, хімічні, технологічні процеси, зокрема і управлінські. Уміння подати свої міркування у вигляді блок-схеми суттєво дисциплінує алгоритмічне мислення фахівців з публічного управління та стає необхідною практичною якістю спеціаліста будь-якої професії. Якщо навчити фахівців складати блок-схеми та створювати текстові алгоритми до розв'язування завдань, то вони зможуть складати алгоритми послідовних управлінських дій набагато швидше та поміркованіше принимать результативні управлінські рішення.

На початку ознайомлення 3 блок-схемами слід фахівцю з'ясувати як описувати життєві процеси, управлінську діяльність сучасного керівника у вигляді розгалуженої структури блок-схем. Наприклад, алгоритми розгалуженої структури . Розгалужена структура передбачає вибір виконання дії залежно від виконання певної умови, при цьому деякі дії можуть не виконуватися взагалі (пропускатися). Проста умова містить два вирази (значення), поєднані знаком операції відношення: $>$ більше за.. < менше за.. ${ }^{3}$ більше або дорівнює... менше або дорівнює ... не 
дорівнює... Результатом перевірки умови є логічний вираз істина, якщо умова виконується, або брехня, якщо умова не виконується.

Після того, як фахівці зможуть перекладати звичайну мову на мову блок-схем, слід пропонувати їм складати блок-схеми розв’язування завдань 3 публічного управління. Перші блок-схеми можуть бути простими для складання, головне, щоб фахівці зрозуміли хід думок та запам'ятали послідовність дій. Наочність блок-схем $\epsilon$ засобом попередження типових помилок суасного керівника. Щоб запобігти таким помилкам, слід фахівцям навчитися ставити завдання, самостійно складати блоксхему в залежності від актуальності запитань.

Ми підтримуємо думку науковця П. Я. Гальперіна , що практичне значення використання блок-схем чи алгоритмічних приписів згідно його теорії є поетапного формування розумових дій та полягає в тому, що процес формування нових дій відбувається легше, без заучування нового матеріалу, так як він засвоюється в процесі виконання алгоритму шляхом мимовільного запам'ятовування [1]. Складена блок-схема розв'язування має спрямувати фахівців у сфері публічного управління та адміністрування на сучасний рівень, які володіють навичками розробки управлінських рішень, вміють аналізувати державну політику, розробляти заходи для ії реалізації та зможуть змінити Україну на краще! [2;3].

Висновки та перспективи подальших досліджень. Таким чином, що спроможність фахівців з публічного управління піддавати алгоритмізації свої дії залежить від рівня його розвитку алгоритмічної компетентності, а саме: мислити алгоритмічними категоріями (знання, мислення, культура), є важливим засобом попередження помилок як під час прийняття результативного управлінського рішення, так і в подальшому, зокрема під час приписи складання алгоритму послідовних управлінських дій фахівцями з публічного управління.

Упровадження інтелектуалізації управління в Україні стикається з низкою проблем щоб фахівцю з публічного управління створювати алгоритми, читати алгоритми та виконувати управлінські дії за складеним алгоритмом, потрібно володіти такими вміннями основами яких $\epsilon$ : алгоритмічне мислення та алгоритмічна культура. Подальшого дослідження потребує методика розвитку алгоритмічної компетентності фахівців в умовах публічного управління та адміністрування. Це сфера, яка пов’язана з вирішенням стратегічних завдань державних органів, підприємств, установ, організацій з урахуванням комплексу зовнішніх і внутрішніх факторів впливу і тенденцій розвитку в конкурентному середовищі, а також в певній галузі суспільного виробництва і держави в цілому. Навчальний план магістратури спеціальності 281 Публічного управління та адміністрування має передбачати розвиток алгоритмічної компетентності (алгоритмічних знань, алгоритмічного мислення, алгоритмічної культури), які формують професійні навички, яких вимагають роботодавці та критичних навичок необхідних для подальшого кар’єрного росту. 


\section{Jimpamypa:}

1. Фридман Л. М. Логико-психологический анализ школьных учебных задач . М. : Педагогика.1977. 208с.

2. Публічне управління : термінол. слов. / уклад. : В. С. Куйбіда, М. М. Білинська, О. М. Петроє та ін. ; за заг. ред. В. С. Куйбіди, М. М. Білинської, О. М. Петроє.Київ : НАДУ. 2018. $224 \mathrm{c}$.

3. Мельник М. Еволюція мережевої готовності країн європейського союзу та України. Збірник наукових праць. Ефективність державного управління. 2012. Вип. 31. С.124-130.

4.Вікепедія.URL: https://uk.wikipedia.org/wiki/\%D0\%90\%D0\%BB\%D0\%B3\%D0\%BE\% D1\%80\%D0\%B8\%D1\%82\%D0\%BC

5. Копаев В. Алгоритм как модель алгоритмического процесса. URL: http://www.rusedu.ru

6. Корольський В. В., Капиносов А. Н. Математична алгоритмічна компетентність: теоретико- методичні основи формування, структура та рівні. Педагогіка вищої та середної школи. 2013. Вип. 37.С. 78-84

\section{References:}

1. Fridman, L.M. (1977). Logical and psychological analysis of school learning problems [Logical and psychological analysis of school learning problems]. Moscow: Pedagogy [in Russian]

2. Kuibida, V.S., Bilynska, M.M., Petroie, O.M., et al. (2018). Publichne upravlinnya [Public management]. Kyiv: NADU [in Ukrainian].

3. Melnyk, M. (2012). Evoliutsiia merezhevoi hotovnosti krain yevropeiskoho soiuzu ta Ukrainy [Evolution of readiness of the krains of the European Union and Ukraine]. Efektyvnist derzhavnoho upravlinnia - The effectiveness of the state government, 31, 124-130 [in Ukrainian].

4. Alhorytm [Algorithm]. uk.wikipedia.org. Retrieved from https://uk.wikipedia.org/wiki/\%D0\%90\%D0\%BB\%D0\%B3\%D0\%BE\%D1\%80\%D0\%B8\%D1\%82\%D 0\%BC [in Ukrainian].

5. Kopaev, O. V. (2003). Algoritm, kak model algoritmicheskogo protsessa [Algorithm as a model of an algorithmic process]. Kyiv: NPU im. M. P. Dragomanova [in Russian]

6. Korolskiy, V.V., Kapinosov, A.N. (2013). Mathematical algorithm competence: theoretical and methodological foundations formulated, the structure is trivial [Mathematical algorithmic competence: theoretical and methodological bases of formation, structure and levels]. Pedahohika vyshchoi ta serednoi shkoly - Pedagogy of Higher and Secondary School, 37, 78-84 [in Ukrainian]. 